\title{
Microclimatological conditions at the Imingfjell mountain, Norway: comparison of model results with observed data
}

\author{
Anastasiia Vasiakina $^{1 *}$, Hans Renssen ${ }^{1}$, Peter Aartsma ${ }^{1}$ and Viktoriia Kurovskaia $^{2}$ \\ ${ }^{1}$ University of South-Eastern Norway, Gullbringvegen, 36, 3800, Bø i Midt-Telemark, Norway \\ ${ }^{2}$ Lomonosov Moscow State University, Leninskie Gory, 1, 119991, Moscow, Russia
}

\begin{abstract}
Models are often used when data is insufficient. However, it is difficult to assess how well they perform, especially for mountainous areas. The Community Land Model 4.5 was selected for testing with the Imingfjell mountain in Norway as a research area. Weather parameters from two nearest meteorological stations and energy fluxes for lichens and shrubs on the Imingfjell were used for comparison with model input and output data, respectively. Calculated by the model temperature from the input was higher by $1-2{ }^{\circ} \mathrm{C}$ than from the stations meaning the model underestimates the Imingfjell elevation by 3 times, possibly due to its spatial resolution. As for output data comparison, mean values for modelled soil heat fluxes slightly differed from field data by only 1-3 $\mathrm{W} / \mathrm{m}^{2}$. However, these similarities cannot be considered significant due to average correlation coefficients $(0.63$ for model/lichen and $0.51-$ model/shrub).
\end{abstract}

\section{Introduction}

Mountains are one of the most hardly accessible territories and, therefore, important objects to study [1]. However, only a small amount of observational data for mountainous areas is available due to the lack of meteorological stations at high altitudes [2]. One of the modern options for obtaining meteorological data for mountain ranges is modelling [3]. However, it is not always possible to verify how reliable the model results are without having initial data for mountain territories. In this research, the Community Land Model (CLM 4.5), provided by the University of Oslo, was used for testing. A special feature of this model is that it can calculate the local energy fluxes for a chosen grid cell, using a few climatic variables as input data. The model has been previously tested, but not for specific conditions of the mountains in South Norway $[4,5]$. Therefore, the purpose of this study was to compare model input and output data with observed data to see how accurate the CLM 4.5. is for mountain areas.

The mountain Imingfjell $\left(60^{\circ} 11^{\prime} 11.7^{\prime \prime} \mathrm{N} 8^{\circ} 34^{\prime} 45.2^{\prime \prime E}\right)$, with an altitude of 1191 meters in Nore og Uvdal Municipality in Buskerud, Norway was chosen as the study object (Fig.1).

\footnotetext{
*Corresponding author: anastasiavasyakina@gmail.com
} 


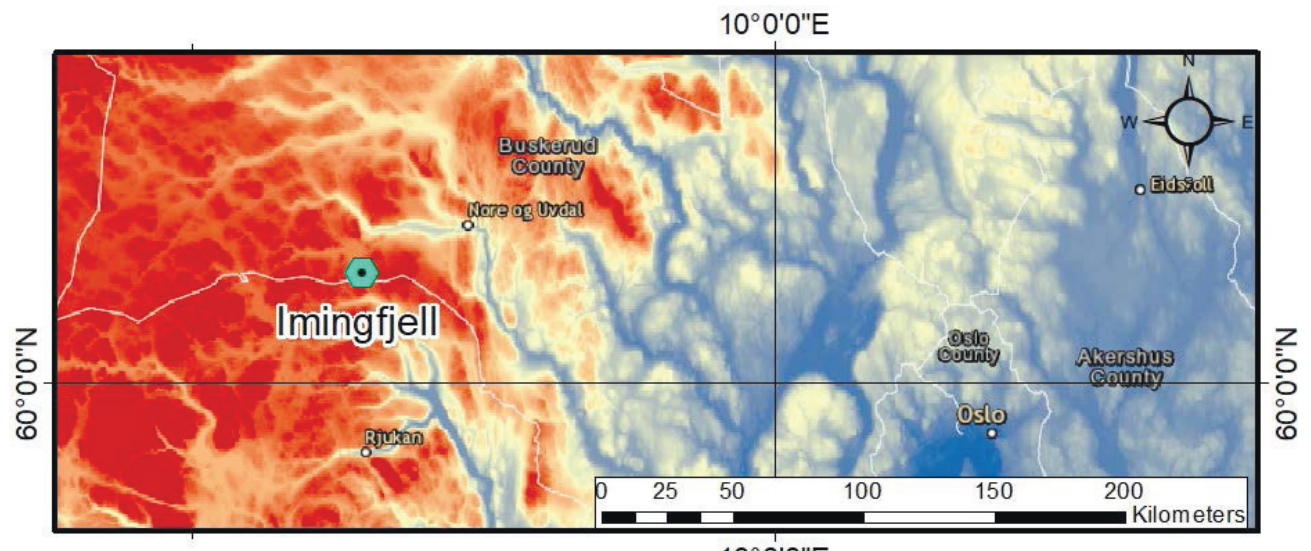

$10^{\circ} 0^{\prime} 0^{\prime \prime E}$

Fig. 1. Location of the Imingfjell mountain (the map was made in ArcMap).

The selected area was divided depending on the dominant vegetation into different plot types (lichens and shrubs) to see the difference between them. This is an area of special interest, because here the impact of climate change on vegetation is studied by the University of South-Eastern Norway (USN).

\section{Methods}

\subsection{Model description}

The Community Land Model (CLM 4.5) is a land model used with the Community Atmosphere Model and the Community Climate System Model [6]. It simulates biogeophysical (surface energy fluxes and hydrology) and biogeochemical processes at the surface and in the soil (Fig.2). CLM 4.5 uses the surface energy, water, and carbon balances for its calculations. A full description of the model and its content are given in the technical description by Oleson et al.[6].

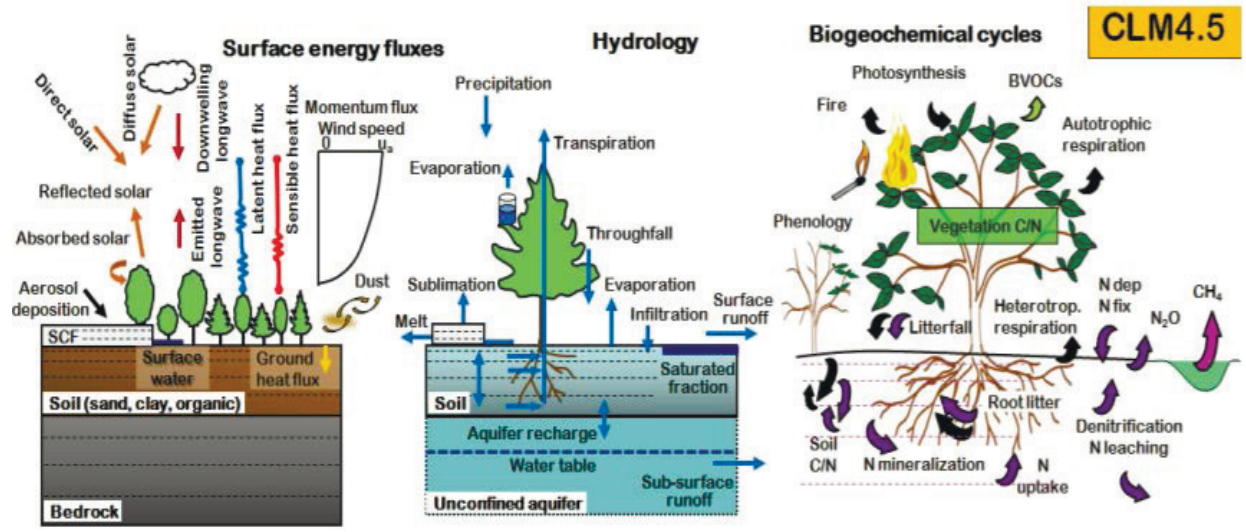

Fig. 2. Land biogeophysical, biochemical and landscape processes simulated by the model [6].

In this model, the Earth surface is divided into grid cells, each of which can have up to three subgrid levels (Fig. 3). The first subgrid level is the land unit which can be presented as glacier, crop, vegetated, lake and/or urban. Some land units can be further divided into a soil/snow column, which is the second subgrid level. The third subgrid level is the plant 
functional types level or PFT. It is used for vegetated land unit and can have up to 16 different PFT (including shrubs) depending on physiology and structure [6]. However, lichens are not presented in vegetated land unit, although the importance of it as a new possible plant functional type was studied [7].

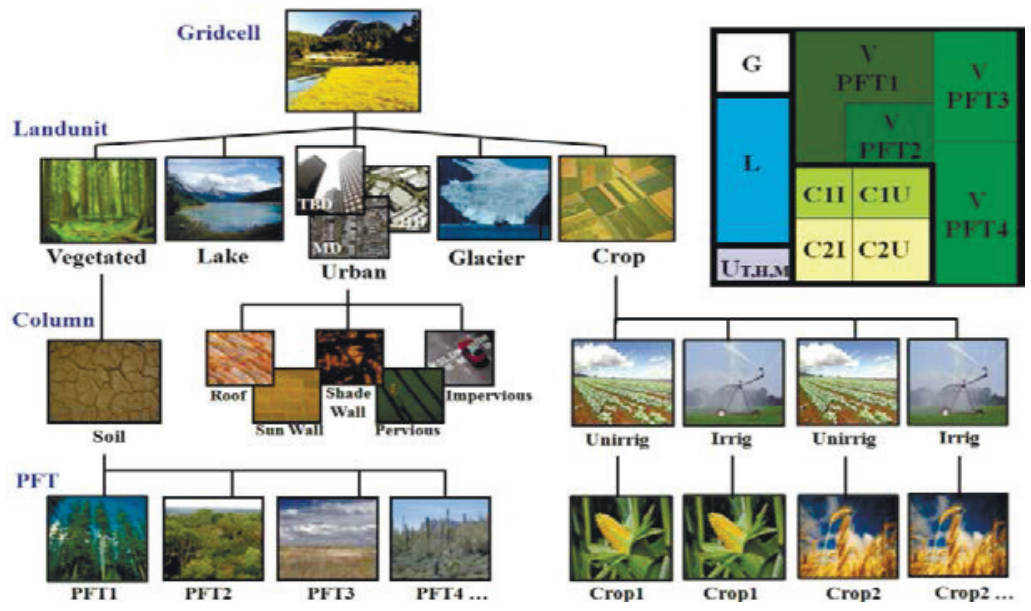

Fig. 3. Configuration of the CLM subgrid hierarchy [6].

The Community Land Model is a one-dimensional model and can be used for the surface of the whole Earth or for a particular region of interest. The area of a single CLM grid cell is 1x1 degree latitude-longitude. The model was run for a single grid cell containing Imingfjell area with PFT such as needleleaf deciduous tree (boreal), broadleaf evergreen shrub (temperate), $C_{3}$ artic grass and $C_{3}$ grass for the period from 1900 to 2016 (input data) and from 1991 to 2016 (output data).

\subsection{Input data}

Input data for the model consists of several weather parameters such as total incident radiation $\left(\mathrm{W} \mathrm{m}{ }^{-2}\right)$, total precipitation $\left(\mathrm{mm} \mathrm{H}_{2} 0 \mathrm{sec}^{-1}\right)$, temperature $(\mathrm{K})$, wind speed $\left(\mathrm{m} \mathrm{s}^{-1}\right)$, surface pressure $(\mathrm{Pa})$ and specific humidity $\left(\mathrm{kg} \mathrm{kg}^{-1}\right)$. Model calculates these parameters through atmospheric model in coupled mode or through an observed dataset in offline mode for a chosen grid cell [6].

The two nearest meteorological stations with the longest available datasets were chosen for a comparison with model input data. Meteorological data were taken from the climate database of the Norwegian Meteorological Institute [8]. The first station is Dagali Lufthavn with an altitude of 798 meters, located $26 \mathrm{~km}$ from Imingfjell. The second station is Tunhovd ( 870 meters altitude) located $32 \mathrm{~km}$ from the research site. The time period of 15 years from 2002-2016 was chosen for the analysis.

We used the barometric formula to calculate the assumed modelled altitude, because it was not readily provided by the model [9].

$$
P=P_{0} \exp (-M g h / R T) \text {, }
$$

where $P$ is the air pressure, $\mathrm{kPa} ; P_{0}$ is the average sea level pressure equal to $101.325 \mathrm{kPa}$; $M$ is the molar mass of Earth's air $\left(0.02896 \mathrm{~kg} \mathrm{~mol}^{-1}\right) ; g$ is the gravitional acceleration $\left(9.807 \mathrm{~m} \mathrm{~s}^{-2}\right) ; h$ is the height over sea level, $\mathrm{m} ; R$ is the universal gas constant equal to $8.3143 \mathrm{~N} \mathrm{~m} \mathrm{~mol}^{-1} \mathrm{~K}^{-1}$; and $T$ is the standard temperature of $288.15 \mathrm{~K}$. 


\subsection{Output data}

Land model output data is the fluxes $\left(\mathrm{W} \mathrm{m}^{-2}\right)$ in energy budget and radiation balance. Comparison of output data was carried out with field data obtained within the $\mathrm{PhD}$ project of Peter Aartsma at USN at the site of Imingfjell. Net radiation, shortwave radiation, longwave radiation, temperature, humidity and soil heat flux for two types of vegetation (lichen and shrubs) were measured. Data was obtained for several days in summer months for 2018 and 2019. In total, the measurements for 44 days are considered here.

Measured daily temperatures varied a lot during those two summers and to analyse this variation more precisely, the research period was divided into three temperature regimes using meteorological data from Dagali Lufthavn. Three periods were divided more or less evenly with each of them having at least 10 days. The first one with the daily mean temperature over $16{ }^{\circ} \mathrm{C}$ was classified as the period with "extreme warm" conditions relative to the long-term summer mean of $12,92^{\circ} \mathrm{C}$. The second one was called the "normal" period with summer temperatures between $12-16{ }^{\circ} \mathrm{C}$. The last one (the "cold" period) was for summer temperatures below $12{ }^{\circ} \mathrm{C}$. From the total of 44 days, 18 days were used for the "normal" period and both the "extreme warm" and "cold" periods each had data for 13 days.

Concerning the model data, 25 years (1992-2016) were analysed to find the years with similar temperature regimes in summer. The warmest available year in the model was 2006 with the mean summer temperature of $14.99{ }^{\circ} \mathrm{C}$. It was chosen for the comparison with "extreme warm" period. The year 2011 with mean summer temperature of $12,93{ }^{\circ} \mathrm{C}$, the closest to the average long-term summer temperature $\left(12,92{ }^{\circ} \mathrm{C}\right)$, was used to analyse the "normal" period. The coldest year from the model was 1993 with mean summer temperature of $10.48^{\circ} \mathrm{C}$. It was used for values from the "cold" period.

\section{Results and discussion}

\subsection{Input data}

Mean monthly values were calculated over a period of 15 years (2002-2016) for model input data. In meteorological data from stations, some months had days with missing data, so mean monthly values were calculated over a different number of years: from 9 to 15 years in the period 2002-2016. The results of the mean monthly temperature are shown as the most representative parameters for analysis (Fig. 4).

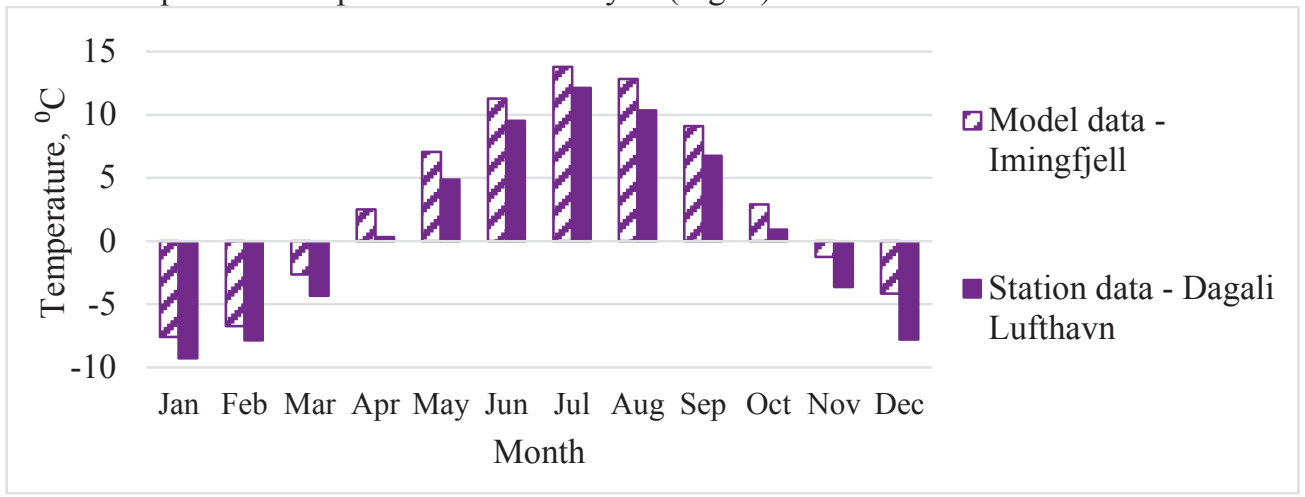

Fig. 4. Mean monthly temperature for model and station datasets. 
The comparison of datasets showed that the temperature from model input data is higher than from the station by $1-2{ }^{\circ} \mathrm{C}$. However, Imingfjell is located higher than the meteorological station (1191 and 798 meters respectively) and temperature values should be noticeably lower than the ones from Dagali Lufthavn. Therefore, the model assumes a lower elevation for Imingfjell then it actually is. This can be explained by the resolution of the model, since it averages values over a sufficiently large area of a grid cell (1x1degree). Using formula (1), the calculated elevation (423 metres) from the model turned out to be around three times less than the actual value (1191 metres). For the correct comparison between model and stations datasets, it is necessary in the future either to manually change an elevation in the model or to correct the input data itself.

\subsection{Output data}

Mean and the range in the values (from minimum to maximum) for three different temperature regimes for model output and measured data were calculated (Table) and plotted (Fig. 5).

Table. Values of soil heat fluxes and its range.

\begin{tabular}{|c|c|c|c|c|}
\hline Dataset & Value & Extreme warm & Normal & Cold \\
\hline \multirow{3}{*}{ Model } & mean & 9.14 & 6.35 & 3.59 \\
\cline { 2 - 5 } & $\max$ & 13.08 & 15.18 & 8.10 \\
\cline { 2 - 5 } & $\min$ & 3.78 & -2.83 & -3.44 \\
\hline \multirow{3}{*}{ Lichen } & mean & 12.25 & 7.39 & 1.74 \\
\cline { 2 - 5 } & $\max$ & 19.58 & 20.70 & 13.68 \\
\cline { 2 - 5 } & $\min$ & 3.88 & 0.59 & -9.40 \\
\hline \multirow{3}{*}{ Shrub } & mean & 7.14 & 5.32 & 2.06 \\
\cline { 2 - 5 } & $\max$ & 11.65 & 9.32 & 6.91 \\
\cline { 2 - 5 } & $\min$ & 2.76 & 2.76 & -6.33 \\
\hline
\end{tabular}

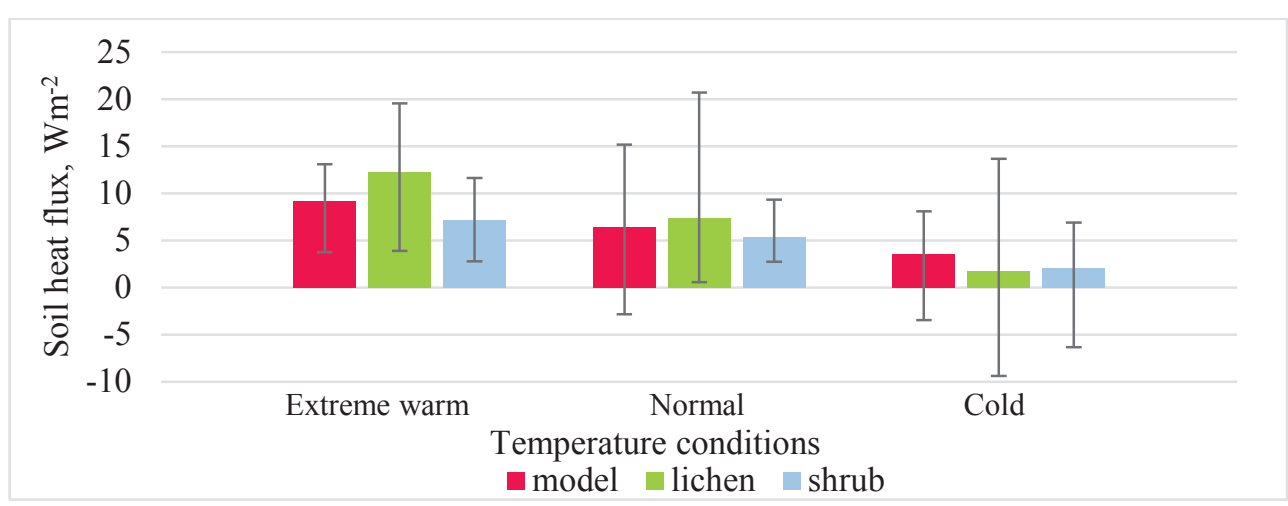

Fig. 5. Mean value of soil heat flux and its range for the model output data, lichen and shrub.

Mean soil heat flux values for model output show relatively similar values compared to measurements for both vegetation types for all three temperature regimes, with a difference of 1 to $3 \mathrm{~W} \mathrm{~m}^{-2}$.

The variation values were calculated by subtracting maximum values from the minimum ones (Table). The highest variations in the range of diurnal soil heat flux were observed for the lichen plots during all temperature regimes, especially during cold one: cold - around $23 \mathrm{~W} \mathrm{~m}^{-2}$; normal $-20 \mathrm{~W} \mathrm{~m}^{-2}$ and extreme warm - $16 \mathrm{~W} \mathrm{~m}^{-2}$. Variations for 
model output data and the shrub sites were similar during extreme warm (both around $9 \mathrm{~W}$ $\mathrm{m}^{-2}$ ) and cold conditions ( $12 \mathrm{~W} \mathrm{~m}^{-2}$ and $13 \mathrm{~W} \mathrm{~m}^{-2}$ respectively). For normal conditions, the model output showed results closer to the lichen plot $-18 \mathrm{~W} \mathrm{~m}^{-2}$.

Correlation coefficients between datasets were calculated to figure out which vegetation type model data resembled the most. For model and lichen, the correlation coefficient was 0.63 and for model and shrub, it was 0.51 .

As we can see from above, correlation coefficients indicate possible positive agreement between model output and vegetation plots but not strong enough to confirm it. The correlation coefficient for lichen is higher than for shrub, meaning that model is not able to calculate energy fluxes values for different types of vegetation with the same accuracy and highly depends on the chosen vegetation type.

\section{Conclusions}

It is still hard to say how accurate the CLM 4.5 model actually is. Our research showed that the model underestimates altitudes and therefore may be inaccurate when used for mountainous areas. However, it should be taken into account that such results were obtained while comparing data from meteorological stations that were located more than 25 $\mathrm{km}$ away from the study site, and might not be fully representative for Imingfjell mountain region.

Additionally, our research area was limited to only one grid cell in the model. Therefore, it is possible that with an increase in both area and number of grid cells, the model results will become more accurate. However, for this it is necessary to continue testing this model for its subsequent improvement.

We would like to thank the University of Oslo, especially Terje Berntsen, for helping us with the Community Land Model 4.5.

\section{References}

1. V.Yu. Khalatov,S.N. Abdul'myanov,Geog. and NRS, Geotopes of mountain territories: Definitions, approaches to the study, protection, 34,14-19 (2013)

2. P.M. Lur'e,V.D. Panov, Russ.Meteorol.Hydro+, Problems of exploration level of hydrometeorological regime of the Northern Caucasus territory, 36, 273-278 (2011)

3. P.R. Lang, F.S. Lombargo,Nova Science Pub, Atmospheric Turbulence, Meteorological Modeling and Aerodynamics, 294-297 (2010)

4. D. Wang, Y. Xu, P. Thornton, A. King, C. Steed, L. Gu, J.Schuchart,Environ. Modell. Softw, A functional test platform for the Community Land Model, 55, 25-31 (2014)

5. D. Enhao, A. Di Vittorio,W.D. Collins,INT J APPL EARTH OBS, Evaluation of hydrologic components of Community Land Model 4 and bias identification, 48, 5-16 (2016)

6. K. Oleson, D. Lawrence, G.B.Bonan,B.A.Drewniak, M. Huang, C.D.Koven, S. Levis, F. Li, W. Riley, Z.M.Subin, S.C. Swenson, P.E. Thornton, A.Bozbiyik, R. Fisher, C. Heald, E.Kluzek, J.-F.Lamarque, P.J. Lawrence, L.R. Leung, W.H. Lipscomb, S. Muszala, D.M. Ricciuto, W.J. Sacks, Y. Sun, J. Tang, Z.-L. Yang, Technical description of version 4.5 of the Community Land Model (CLM)(2013)

7. J.Bjordal, UiO, Potential Implications of Lichen Cover for the Surface Energy Balance Implementing Lichen as a new Plant Functional Type in the Community Land Model (CLM4.5) (2018)

8. MET Norway, eKlima [URL]:http.//eklima.met.no/ (Accessed 19.08.19)

9. A. Svirin, Barometric Formula[URL]: https://www.math24.net/barometric-formula/ (Accessed 23.10.19) 